Article

\title{
Reporter Assay for Endo/Lysosomal Escape of Toxin-Based Therapeutics
}

\author{
Roger Gilabert-Oriol ${ }^{1}$, Mayank Thakur ${ }^{1, *}$, Benedicta von Mallinckrodt ${ }^{1}$, Cheenu Bhargava ${ }^{1}$, \\ Burkhard Wiesner ${ }^{2}$, Jenny Eichhorst ${ }^{2}$, Matthias F. Melzig ${ }^{3}$, Hendrik Fuchs ${ }^{1}$ and \\ Alexander Weng ${ }^{1,4, *}$
}

1 Institute of Laboratory Medicine, Clinical Chemistry and Pathobiochemistry, Charité-Universitätsmedizin Berlin, Campus Virchow-Klinikum, Augustenburger Platz 1, Berlin D-13353, Germany; E-Mails: roger.gilabert-oriol@charite.de (R.G.-O.); benedicta.von-mallinckrodt@charite.de (B.M.); cheenu.bhargava@charite.de (C.B.); hendrik.fuchs@charite.de (H.F.)

2 Leibnizinstitut für Molekulare Pharmakologie (FMP), Berlin D-13125, Germany; E-Mails: wiesner@fmp-berlin.de (B.W.); eichhorst@fmp-berlin.de (J.E.)

3 Institute of Pharmacy, Freie Universität Berlin, Königin-Luise-Straße 2 + 4, Berlin D-14195, Germany; E-Mail: melzig@zedat.fu-berlin.de

4 Wolfson Centre for Gene Therapy of Childhood Disease, University College London-Institute of Child Health, London, 30 Guilford Street, London WC 1N 1EH, UK

* Authors to whom correspondence should be addressed; E-Mails: mayank.thakur@charite.de (M.T.); a.weng@ucl.ac.uk (A.W.); Tel.: +49-30-450-569206 (M.T.); +44-207-905-2817 (A.W.); Fax: +49-30-450-569900 (M.T.); +44-207-905-2810 (A.W.).

Received: 21 March 2014; in revised form: 6 May 2014 / Accepted: 8 May 2014 /

Published: 22 May 2014

\begin{abstract}
Protein-based therapeutics with cytosolic targets are capable of exhibiting their therapeutic effect once they have escaped from the endosomes or lysosomes. In this study, the reporters - horseradish peroxidase (HRP), Alexa Fluor 488 ( ${ }^{\text {Alexa }}$ ) and ricin A-chain (RTA) - were investigated for their capacity to monitor the endo/lysosomal escape of the ribosome-inactivating protein, saporin. The conjugates-saporin-HRP, Alexa ${ }^{\text {saporin and }}$ saporin-KQ-RTA — were constructed, and the endo/lysosomal escape of these conjugates alone (lack of endo/lysosomal release) or in combination with certain structurally-specific triterpenoidal saponins (efficient endo/lysosomal escape) was characterized. HRP failed in reporting the endo/lysosomal escape of saporin. Contrastingly, Alexa Fluor 488 successfully allowed the report of the process at a toxin concentration of $1000 \mathrm{nM}$. In addition, single
\end{abstract}


endo/lysosome analysis facilitated the determination of the amount of ${ }^{\text {Alexa }}$ saporin released from each vesicle. RTA was also successful in reporting the endo/lysosomal escape of the enzymatically inactive mutant, saporin-KQ, but in this case, the sensitivity of the method reached a toxin concentration of $10 \mathrm{nM}$. In conclusion, the simultaneous usage of Alexa Fluor 488 and RTA as reporters may provide the possibility of monitoring the endo/lysosomal escape of protein-based therapeutics in the concentration range of $10-1000 \mathrm{nM}$.

Keywords: endosomal escape; reporter assay; protein therapeutics; ribosome inactivating proteins; horseradish peroxidase; Alexa Fluor 488; ricin A-chain; saporin; triterpenoidal saponins

\section{Introduction}

Endo/lysosomal escape is a key step for protein-based therapeutics that exhibit their effect in the cytosol [1]. In general, these kinds of therapeutics are internalized in the cell by a process of endocytosis, which consists of the formation of invaginations in the cell membrane and the subsequent creation of vesicles, called endosomes, that entrap the protein [2]. Endosomes thereafter mature as late endosomes and, finally, to lysosomes. The internal conditions of these vesicles are regulated at each step by certain specific membrane proteins, such as V-ATPase, that progressively acidifies the intravesicular milieu [3]. During the process of maturation, the $\mathrm{pH}$ values of the vesicles decrease from the extracellular environment (7.4) to early endosomes (6.1-6.8), late endosomes (4.8-6.0) and lysosomes (4.5) [4]. Most importantly, protein-based therapeutics that exert their effect in the cytosol must escape from the endosomes to successfully reach their intracellular targets and exhibit their mechanism of action [5]. Failure to escape the endo/lysosomes leads to the entrapment and subsequent degradation of the protein in the lysosomes [6].

Some bacterial toxins present diverse mechanisms to escape from endosomes and trigger their highly cytotoxic effects. Diphtheria toxin from Corynebacterium diphtheria is internalized by clathrin-mediated endocytosis and entrapped first in early endosomes and, subsequently, in late endosomes [7]. It is in these late vesicles where the toxin is able to translocate through the endosomal membrane and reach its target, eukaryotic elongation factor 2 (EF2), in the cytosol [8]. Anthrax toxin from Bacillus anthracis is another example of the relevance of the endosomal escape for the successful action of a protein. Anthrax toxin is similarly internalized by clathrin-mediated endocytosis to early and late endosomes, and it will only cause its effect on the mitogen-activated protein kinase kinases (MAPKK) once it has escaped from the late endosomes [9].

Furthermore, plant toxins, such as ribosome-inactivating proteins (RIPs), must also escape from endosomes to reach the cytosol and cleave the 28S rRNA, which will result in apoptosis and cell death [10]. Type II RIPs, such as ricin from Ricinus communis L. (comprised of an enzymatic domain and a lectin-binding domain), enter the cell by receptor-mediated endocytosis and follow a complex cell trafficking via retrograde transport and endoplasmic reticulum-associated degradation (ERAD) to finally reach the cytosolic target [11]. In contrast, type I RIPs, such as saporin from Saponaria officinalis L. (consisting of only an enzymatic domain and lacking the cell-binding domain), are internalized, probably by receptor-independent endocytosis [12], and accumulate in late endosomes 
and lysosomes [13], where they get degraded [14]. Type I RIPs can only exhibit cytotoxicity if they can efficiently escape from the endo/lysosomes. In the case of saporin at lower concentrations, this phenomenon may only happen in the presence of certain structurally-specific triterpenoidal saponins, such as SO1861, which naturally occur in the same plant [15]. These triterpenoidal saponins specifically mediate the endo/lysosomal escape of saporin at non-permeabilizing concentrations and the endo/lysosomal membranes remain intact during this process [16].

The successful endo/lysosomal escape in the case of toxins is typically evaluated considering the cytotoxicity of the protein, which will solely appear if the toxin has efficiently crossed the endo/lysosomal membrane to the cytosol. However, for the evaluation of endo/lysosomal escape in the case of other protein-based therapeutics, which are not toxic, the use of a reporter for the endo/lysosomal escape may be required.

In this study, three different reporters for endo/lysosomal escape have been investigated. The reporters were based on the determination of peroxidase activity (horseradish peroxidase), fluorescence (small fluorophore Alexa Fluor 488) and evaluation of cytotoxicity (ricin A-chain). The naturally occurring phenomenon of endo/lysosomal escape enhancement of saporin in combination with structurally-specific triterpenoidal saponins (SA1641 and SO1861) [13,15] was used as a basis to distinguish between the entrapment of the toxin in the endo/lysosomes (saporin alone) and its endo/lysosomal release (saporin plus triterpenoidal saponin). In case of ricin A-chain as a reporter, cytotoxicity is the readout of the experiment. Therefore, a previously described enzymatically inactive variant of saporin (saporin-KQ) [17] was used as a protein that escapes from endo/lysosomes in the presence of triterpenoidal saponins, but that lacks cytotoxic properties.

\section{Results and Discussion}

\subsection{Horseradish Peroxidase As a Reporter}

The first reporter for endo/lysosomal escape that was investigated in this study was horseradish peroxidase (HRP). For this purpose, saporin (recombinantly expressed and purified by Ni- nitrilotriacetic acid (NTA) chromatography; see Figure S1 in the Supplementary) was chemically conjugated to HRP via a covalent linkage, and the reaction mixture was analysed by SDS-PAGE (Figure 1A). A diffused band with high molecular mass was identified by the reaction mixture in the gel. This band in all probability contained conjugates of saporin-HRP with different molecular ratios of saporin to HRP. Furthermore, a band with the same molecular mass as HRP was observed, while no unconjugated saporin was detected in the reaction mixture.

To remove unconjugated HRP, the reaction mixture was purified by Ni-NTA chromatography. The flow-through, wash and elution fractions were analysed by SDS-PAGE (Figure 1B). Unconjugated HRP that did not contain the $6 \times$ his-tag was directly eluted in the flow-through and during the washing steps. A certain amount of saporin-HRP was eluted in the flow-through and subsequent washing steps, apparently because the cross-linking reaction of saporin to HRP resulted in the partial masking of the $6 \times$ his-tag and prevented the affinity binding of a subset of saporin-HRP to the column. However, saporin-HRP with accessible $6 \times$ his-tag bound strongly to the column and was eluted in Fractions 1-3 at $62 \mathrm{mM}$ imidazole (see arrow in Figure 1B). Fractions containing purified saporin-HRP were 
separately dialyzed and concentrated. The total yield for saporin-HRP was around $1.4 \mathrm{mg}$ of conjugate, and the relative outcome was $14 \%$ of the protein input (saporin plus HRP).

Figure 1. Chemical conjugation, purification and characterization of saporin-HRP. (A) Cross-linkage of saporin and HRP. The reaction mixture was directly analysed by SDS-PAGE. Saporin and HRP served as unconjugated controls; (B) Purification of saporin-HRP by Ni-NTA chromatography with increasing concentrations of imidazole in the elution buffer. All fractions were assessed by SDS-PAGE. Saporin-HRP was eluted in Fractions 1-3 at $62 \mathrm{mM}$ imidazole (see arrow); (C) Validation of the chemical conjugation of saporin and HRP. Saporin-HRP was analysed by SDS-PAGE, and the conjugate was visualized in the gel (see arrow). Saporin-HRP was analysed by Western blot with a primary polyclonal antibody against saporin. Saporin and the conjugate (see arrow) were specifically detected in the membrane; (D) Peroxidase activity of saporin-HRP. A directly proportional correlation between absorbance and concentration was observed from 0.1 to $10 \mathrm{nM}$ saporin-HRP. Each data point is the mean $\pm \mathrm{SD}, n=3$; Comparison of the cytotoxicity of (E) saporin and (F) saporin-HRP in the presence of SA1641. ECV-304 cells (4000 cells/well) were treated with saporin or saporin-HRP in a concentration range from 0.01 to $100 \mathrm{nM}$ alone or in combination with SA1641 (final concentration of $5 \mu \mathrm{g} / \mathrm{mL}$ ) for $48 \mathrm{~h}$. Cell viability was determined by the MTT assay. Data represents the mean $\pm \mathrm{SD}, n=4$.
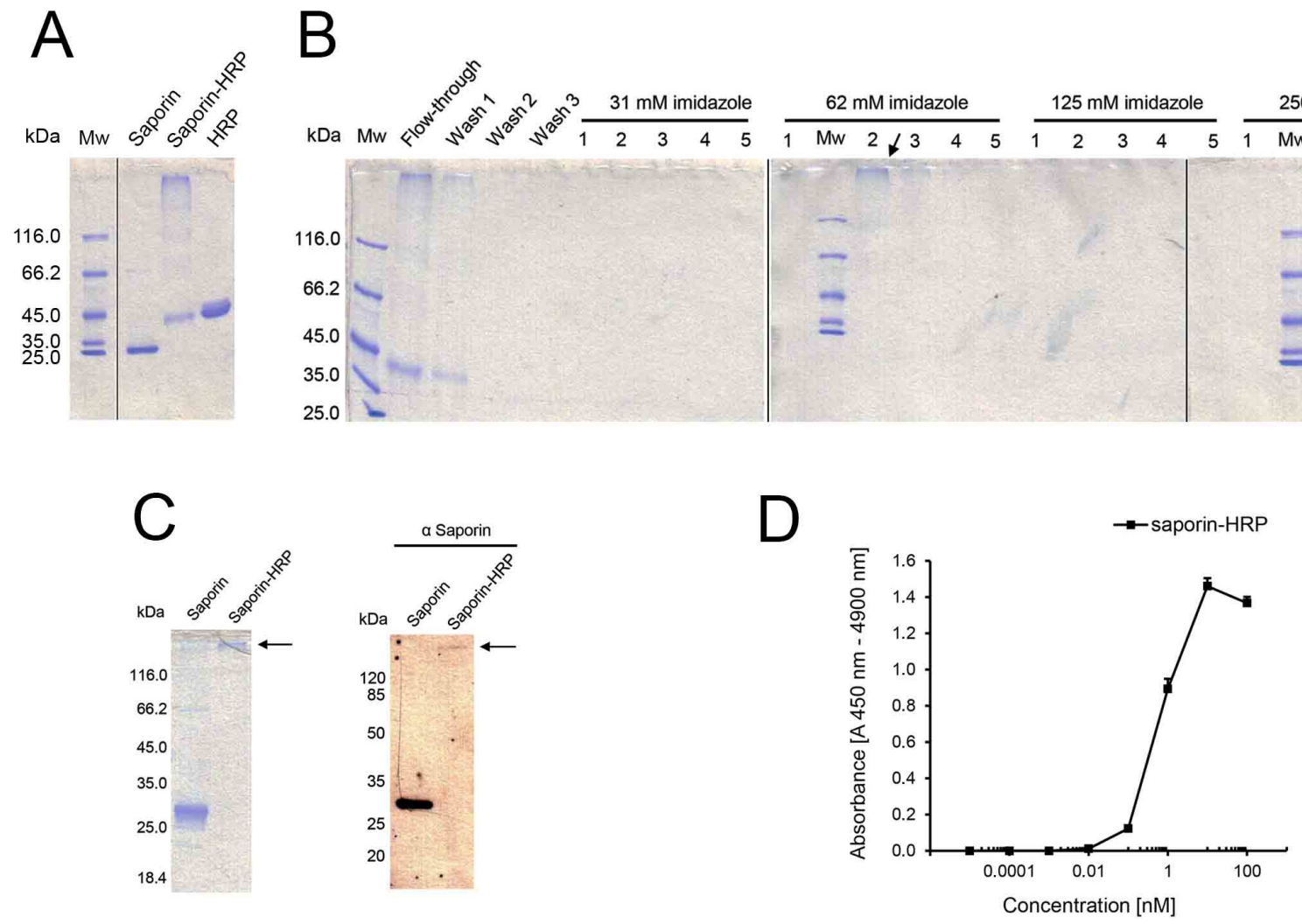
Figure 1. Cont.
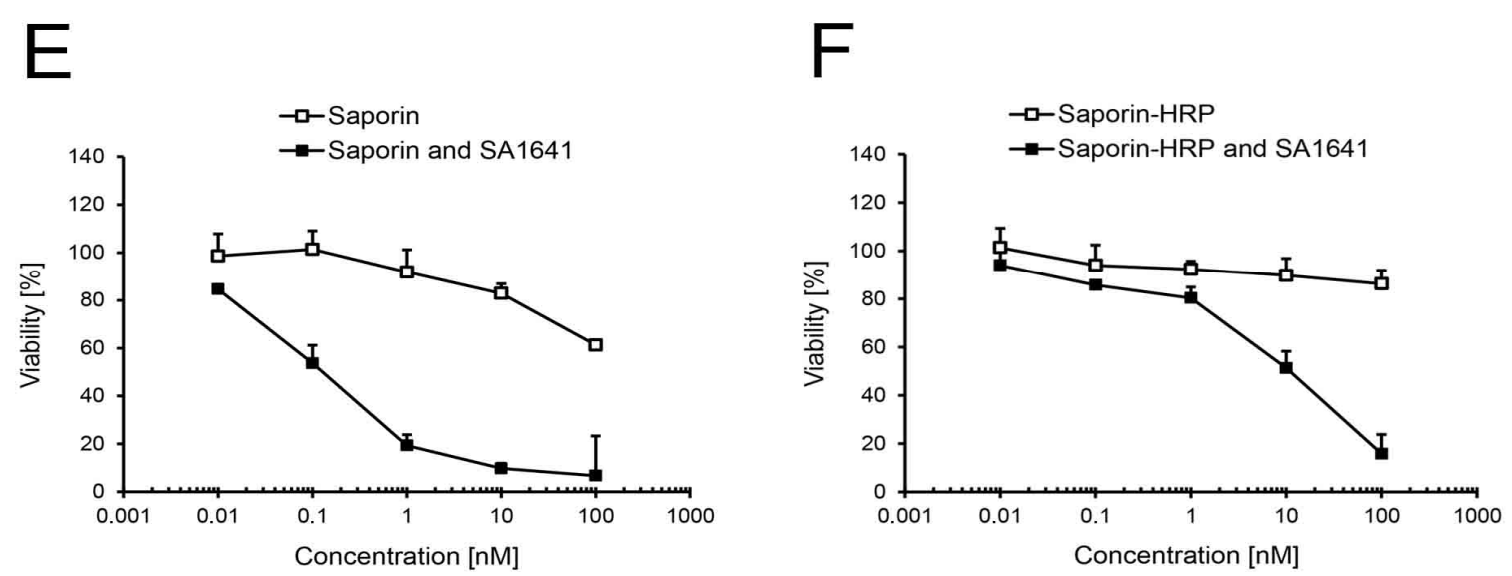

Although chemical conjugation was already validated by the specific binding of the conjugate (containing the $6 \times$ his-tag in the saporin moiety) to the Ni-NTA agarose and detection of the high molecular mass conjugate after SDS-PAGE (see Figure 1B), validation of the cross-linking reaction was confirmed again by western blot with a primary polyclonal antibody against saporin (Figure 1C). Both saporin (intense band in the unconjugated control) and saporin-HRP (slight band) were specifically detected. Unconjugated saporin was not detected in the conjugate sample.

To determine if the peroxidase activity of HRP had been affected by the chemical conjugation process and to define the sensitivity of the conjugate, peroxidase activity of saporin-HRP was measured at a series of concentrations ranging from 0.00001 to $100 \mathrm{nM}$ (Figure 1D). In the lower concentrations $(0.00001$ to $0.01 \mathrm{nM})$, the enzymatic activity of saporin-HRP was not detectible. The first detectable signals in the presence of saporin-HRP appeared at concentrations between 0.01 and $0.1 \mathrm{nM}$ of the conjugate. Then, a linear correlation between the absorbance and concentration of the conjugate was observed in the range from 0.1 to $10 \mathrm{nM}$ saporin-HRP. Finally, for concentrations higher than $10 \mathrm{nM}$, a saturation of the absorbance signal was recorded.

The $N$-glycosidase activity of saporin-HRP was compared to that of saporin to investigate if the enzymatic activity of the toxic moiety had been influenced by the chemical conjugation process. Saporin-HRP released $46.3 \mathrm{pmol}$ adenine/pmol toxin/h after incubation with herring sperm DNA. Since the adenine release of saporin was calculated to $117.6 \mathrm{pmol}$ adenine $/ \mathrm{pmol}$ toxin $/ \mathrm{h}$, the $N$-glycosidase activity of saporin-HRP was reduced to $39.3 \%$. However, saporin-HRP still presented enzymatic activity and was therefore suitable for further studies.

The effect of triterpenoidal saponins (SA1641) on the enhancement of the endo/lysosomal escape of saporin-HRP was compared to that on saporin on ECV-304 cells. In the case of saporin (Figure 1E), the toxin alone showed cytotoxic effects and caused a reduction of the viability to $61 \%$ at a concentration of $100 \mathrm{nM}$. In combination with SA1641 $(5 \mu \mathrm{g} / \mathrm{mL})$, saporin cytotoxicity was drastically enhanced, causing a reduction of cell viability to $54 \%$ at a concentration of $0.1 \mathrm{nM}$.

In the case of saporin-HRP (Figure 1F), no cytotoxicity was shown up to a concentration of $100 \mathrm{nM}$. However, in the presence of SA1641, saporin-HRP exerted cytotoxicity at the two highest concentrations tested: cell viability was reduced to $51 \%$ at $10 \mathrm{nM}$ and to $16 \%$ at $100 \mathrm{nM}$. It is important to note that the cytotoxicity enhancement also took place when saporin was chemically 
coupled to HRP, therefore indicating that the endo/lysosomal escape of saporin in combination with triterpenoidal saponins was coherent, even after coupling to the reporter, and that saporin has a general potential as a molecular drag.

In order to measure the specific augmentation of the endo/lysosomal release of saporin-HRP mediated by triterpenoidal saponins, cells were first treated either with saporin-HRP $(100 \mathrm{nM})$ or with the combination of saporin-HRP and SA1641 $(5 \mu \mathrm{g} / \mathrm{mL})$. After an incubation time of $6 \mathrm{~h}$ and cell fractionation, the endo/lysosomal release of the toxin-reporter conjugate was evaluated by measuring peroxidase activity in the cytosolic fraction and in the lysosomal fraction. The ratio of the peroxidase activity in the cytosolic fraction and the peroxidase activity in the lysosomal fraction $(\mathrm{CF} / \mathrm{LF})$ is proportional to the relative amount of saporin-HRP released to the cytosol.

Unfortunately, the $\mathrm{CF} / \mathrm{LF}$ value mirrored contradictory results in repeated experiments. Peroxidase activity detected in the cytosolic fractions was very close to the detection limit $\left(\mathrm{A}_{450-490 \mathrm{~nm}}=0.018-0.030\right)$, and therefore, small variations in the absorbance values greatly influenced the CF/LF ratio. In one example, the CF/LF value of the cells treated with SA1641 (0.082) was higher than that of the cells treated without the triterpenoidal saponin (0.072). However, in another example, the CF/LF value of the cells treated with SA1641 (0.107) was lower than that of the cells treated without the triterpenoidal saponin (0.151). In short, the measurements close to the detection limit resulted in a bad reproducibility and prevented the precise calculation of ratios representing the endo/lysosomal escape of saporin-HRP in the presence or absence of triterpenoidal saponins.

In an alternative approach, the endo/lysosomal escape of saporin-HRP was evaluated in isolated organelles preloaded with the conjugate. To determine the highest non-permeabilizing concentration of triterpenoidal saponins, short-term permeabilizing effects of SA1641 on lysosomal membranes from isolated organelles were measured using the lysosomal enzyme $\beta$ - $N$-acetylglucosaminidase (NAG) release assay (Figure 2A). In the case of digitonin (positive control, highly lytic saponin isolated from Digitalis purpurea L.), slight membrane permeabilizing effects on the lysosomal membrane were first observed at a concentration of $5 \mu \mathrm{M}(6.15 \mu \mathrm{g} / \mathrm{mL})$. The permeabilizing effects of digitonin progressively increased as the concentration was augmented to $50 \mu \mathrm{M}(61.47 \mu \mathrm{g} / \mathrm{mL})$. In the case of $\alpha$-hederin (negative control, non-lytic saponin isolated from Hedera helix L.), no membrane permeabilizing effects were observed on the lysosomal membrane. Even at the highest concentration tested, only a very slight release of NAG was measured. SA1641 had substantial membrane permeabilizing effects at a concentration of $50 \mu \mathrm{M}(82.05 \mu \mathrm{g} / \mathrm{mL})$. However, at lower concentrations, SA1641 did not present any permeabilizing effects on lysosomal membranes, and the absorbance values were comparable to those of $\alpha$-hederin.

In the case of a specific augmentation of the endo/lysosomal release of saporin-HRP in the presence of SA1641, higher amounts of the conjugate are expected to be released at low non-membrane permeabilizing concentrations of SA1641 (lower than $50 \mu \mathrm{M}$ or $82.05 \mu \mathrm{g} / \mathrm{mL}$ ). In such a case, saporin-HRP will be released from the lysosomes, due to a specific interaction with SA1641.

Nevertheless, no such specific release of saporin-HRP was observed in the presence of SA1641 (Figure 2B). Although cytotoxicity enhancement is already observed at $5 \mu \mathrm{g} / \mathrm{mL}$ of SA1641 (Figure 1F), no specific endo/lysosomal release of saporin-HRP was observed at this concentration. The endo/lysosomal release of saporin-HRP increased slightly as the concentration was augmented to 30,40 and $50 \mu \mathrm{M}(49.23,64.64$ and $82.05 \mu \mathrm{g} / \mathrm{mL}$, respectively), most probably attributed to unspecific 
membrane permeabilizing effects. In the case of digitonin, the high endo/lysosomal release of saporin-HRP was shown at 30, 40 and $50 \mu \mathrm{M}(36.88,49.17$ and $61.47 \mu \mathrm{g} / \mathrm{mL}$, respectively), due to disruption of lysosomal membranes. In the case of $\alpha$-hederin, no endo/lysosomal release of saporin-HRP was observed at all the concentrations tested. Regrettably, the reporter assay for endo/lysosomal escape using HRP is not suitable to quantify the endo/lysosomal release of protein-based therapeutics.

Figure 2. HRP as a reporter for endo/lysosomal escape in isolated organelles. Lysosomes were isolated by cell fractionation form ECV-304 cells $\left(3 \times 10^{7}\right.$ cells $)$. (A) First, the permeabilizing effects of SA1641 on the lysosomal membranes were evaluated by the $\beta$ - $N$-acetylglucosaminidase (NAG) release assay. The permeabilizing effects of digitonin (highly lytic saponin) and $\alpha$-hederin (non-lytic saponin) were simultaneously determined as controls; (B) Thereafter, the endo/lysosomal escape enhancement of saporin-HRP observed in the cytotoxicity assay in Figure $1 \mathrm{~F}$ was tried, to monitor in isolated lysosomes loaded with saporin-HRP (from cells previously treated with the conjugate at $100 \mathrm{nM}$ and $37{ }^{\circ} \mathrm{C}$ for $6 \mathrm{~h}$ ) by determination of the peroxidase activity. Saponin concentrations are shown in $\mu \mathrm{M}$ to allow a better comparison. Each data point represents the mean $\pm \mathrm{SD}, n=3$.
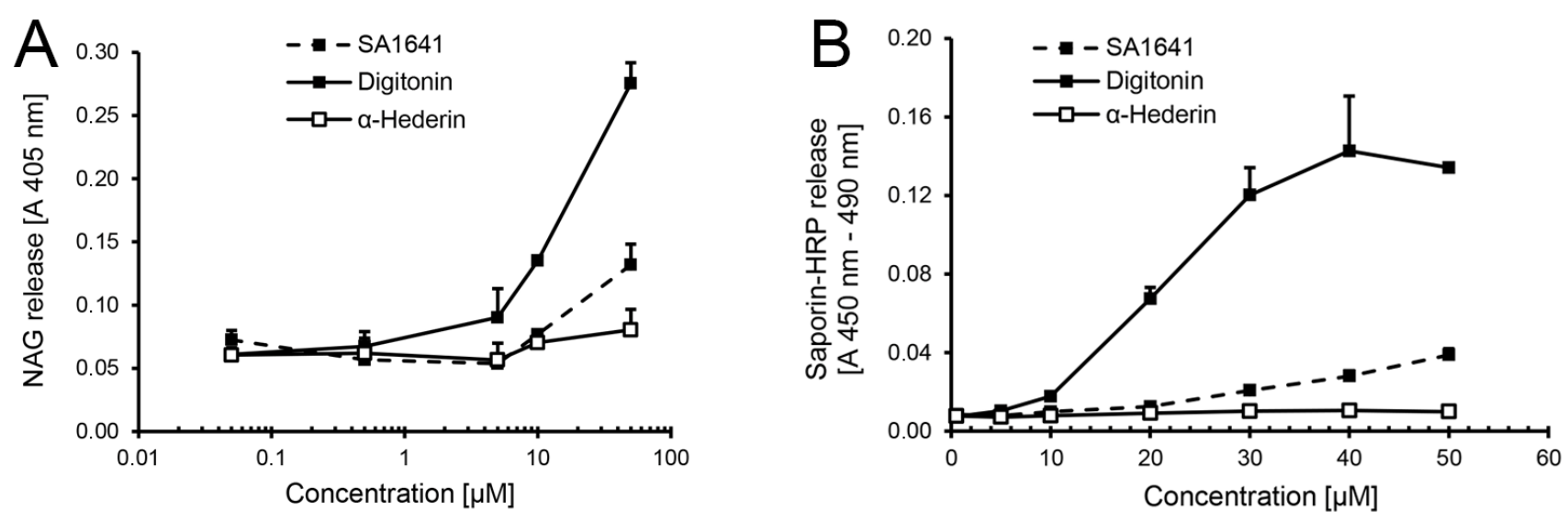

It is known from previous studies that the release of diphtheria toxin's catalytic (C) domain from endosomes into the cytosol requires a host cell cytosolic translocation factor complex, which consists of the chaperone heat shock protein 90 (Hsp 90) and thioredoxin reductase [18]. Furthermore, host cell Hsp 90 is also essential for the translocation of Clostridium botulinum $\mathrm{C} 2$ toxin from endosomes into the cytosol [19] and for the transfer of the cholera toxin A1 subunit from the endoplasmic reticulum to the cytosol [20]. Similarly, since a certain amount of saporin-HRP must definitively escape from the endo/lysosomes in the presence of triterpenoidal saponins, because cytotoxicity was observed (see the cytotoxicity enhancement at $3.05 \mu \mathrm{M}$ or $5 \mu \mathrm{g} / \mathrm{mL}$ of SA1641 in Figure 1F), a possible explanation for the lack of saporin-HRP release from the isolated organelles (see saporin-HRP release at $5 \mu \mathrm{M}$ or $8.21 \mu \mathrm{g} / \mathrm{mL}$ SA1641 in Figure 2B) is the necessity of a certain cytosolic machinery to efficiently mediate the specific endo/lysosomal release of saporin (or saporin conjugates, such as saporin-HRP) in the presence of triterpenoidal saponins. An alternative hypothesis is that the amount of saporin-HRP that escapes from the isolated endo/lysosomes is so low that its measurement remains under the limit of detection, but it is high enough to cause cell death. 


\subsection{Alexa Fluor 488 As a Reporter}

The second reporter that was investigated was Alexa Fluor 488. Recombinantly expressed saporin was labelled with Alexa Fluor 488, and the conjugate ( ${ }^{\text {Alexa }}$ saporin) was administered to cells in the presence of SA1641 to visualize the endo/lysosomal escape of saporin by live cell imaging (Figure 3).

After the incubation of cells with ${ }^{\text {Alexa }}$ saporin for $3 \mathrm{~h}$, only the accumulation of the labelled protein (emitting green fluorescence) was observed inside the cell, but no endo/lysosomal escape was detected. Cells treated with ${ }^{\text {Alexa }}$ saporin under the same conditions for $6 \mathrm{~h}$ indicated that the toxin accumulates in acidic organelles, namely late endosomes and lysosomes, but is not released to the cytosol [13]. Furthermore, in the present experiment, ${ }^{\text {Alexa }}$ saporin did presumably not have any cytotoxic effects in the short incubation time of $3 \mathrm{~h}$, because the morphology of the cells was intact. At that moment $(\mathrm{t}=0 \mathrm{~s})$, triterpenoidal SA1641 was added to the cells to a final concentration of $10 \mu \mathrm{g} / \mathrm{mL}$, and initially, no changes were observed. However, after $1400 \mathrm{~s}$ of addition of SA1641, a diffusion of green fluorescence started to become visible in a cell at the top right of the fluorescence microscopy picture. This diffusion was limited to the intracellular space and was associated with the endo/lysosomal escape of ${ }^{\text {Alexa }}$ saporin.

Within the next $300 \mathrm{~s}$ (from $\mathrm{t}=1400 \mathrm{~s}$ to $\mathrm{t}=1680 \mathrm{~s}$ ), the intensity of fluorescence in the cell increased rapidly and reached a saturation point, indicating a complete release of ${ }^{\text {Alexa }}$ saporin into the cytosol. Furthermore, after $2100 \mathrm{~s}$, fluorescence diffusion appeared in two more cells: one at the top centre and another one at the bottom left of the fluorescence image. After $2800 \mathrm{~s}$, the fluorescence diffusion was observed in seven cells, and after $3500 \mathrm{~s}$, a total of nine cells exhibited diffused fluorescence in the cytosol. It is remarkable that the diffusion of the fluorescence occurred only in the intracellular space, but did not cross the cell membrane, indicating that SA1641 did not cause unspecific cell membrane permeabilization, but specifically mediated the endo/lysosomal escape of ${ }^{\text {Alexa }}$ saporin. Only after the addition of SA1641 at a high concentration $(80 \mu \mathrm{g} / \mathrm{mL})$, cell membranes were unspecifically permeabilized, and fluorescence diffusion disappeared quickly, due to the leakage of Alexa saporin from the cytosol to the extracellular space. A video comprising the whole sequence of images is available in the Supplementary (Video S1). The single cell analysis derived from the fluorescence images in the Video S1, but not the fluorescence images themselves, was previously published [13].

In addition, the endo/lysosomal escape was analysed in this study for 16 single endo/lysosomes identified in the fluorescence images from $2050 \mathrm{~s}$ to $3290 \mathrm{~s}$ at a final concentration of $10 \mu \mathrm{g} / \mathrm{mL}$ (Figure 4A). Regions of interest were defined for each endo/lysosome, and the amount of green fluorescence diffusion that corresponds to the released amount of ${ }^{\text {Alexa }}$ saporin was individually evaluated in the case of each endo/lysosome. Furthermore, in a second experiment, where cells were monitored for $7200 \mathrm{~s}$ after the addition of SA1641, the fluorescence intensity of ${ }^{\text {Alexa }}$ saporin released from individual endo/lysosomes was plotted against the time (from $t=2400 \mathrm{~s}$ to $t=4200 \mathrm{~s}$ ) (Figure 4B). A curve for each of the 16 endo/lysosomes was obtained and every curve presented a particular behaviour, showing the differences in the release rate of ${ }^{\text {Alexa }}$ saporin from one endo/lysosome to another. 
Figure 3. Alexa Fluor 488 as a reporter for endo/lysosomal escape in live cell imaging. The report of the naturally occurring phenomenon of the endo/lysosomal escape enhancement of saporin (in this case ${ }^{\text {Alexa }}$ saporin) was assayed by constant measurement of fluorescence. ECV-304 cells were incubated with $1000 \mathrm{nM}{ }^{\text {Alexa }}$ saporin at $37{ }^{\circ} \mathrm{C}$ for $3 \mathrm{~h}$. Afterwards, most of the internalized toxin accumulated in intracellular vesicles. ${ }^{\text {Alexa }}$ saporin is visualized in green fluorescence, cell membranes in magenta and cell nuclei in cyan. The addition of $10 \mu \mathrm{g} / \mathrm{mL}$ SA1641 (non-cytotoxic concentration) was defined as $\mathrm{t}=0 \mathrm{~s}$. Green colouring of the cells reflects the release of ${ }^{\text {Alexa }}$ saporin (from $\mathrm{t}=1400 \mathrm{~s}$ to $\mathrm{t}=3500 \mathrm{~s})$. To finish the experiment, SA1641 was added $(\mathrm{t}=3640 \mathrm{~s})$ to a final concentration of $80 \mu \mathrm{g} / \mathrm{mL}$ (cytotoxic concentration), which results in total cell membrane disruption (from $\mathrm{t}=3640 \mathrm{~s}$ to $\mathrm{t}=3700 \mathrm{~s}$ ).

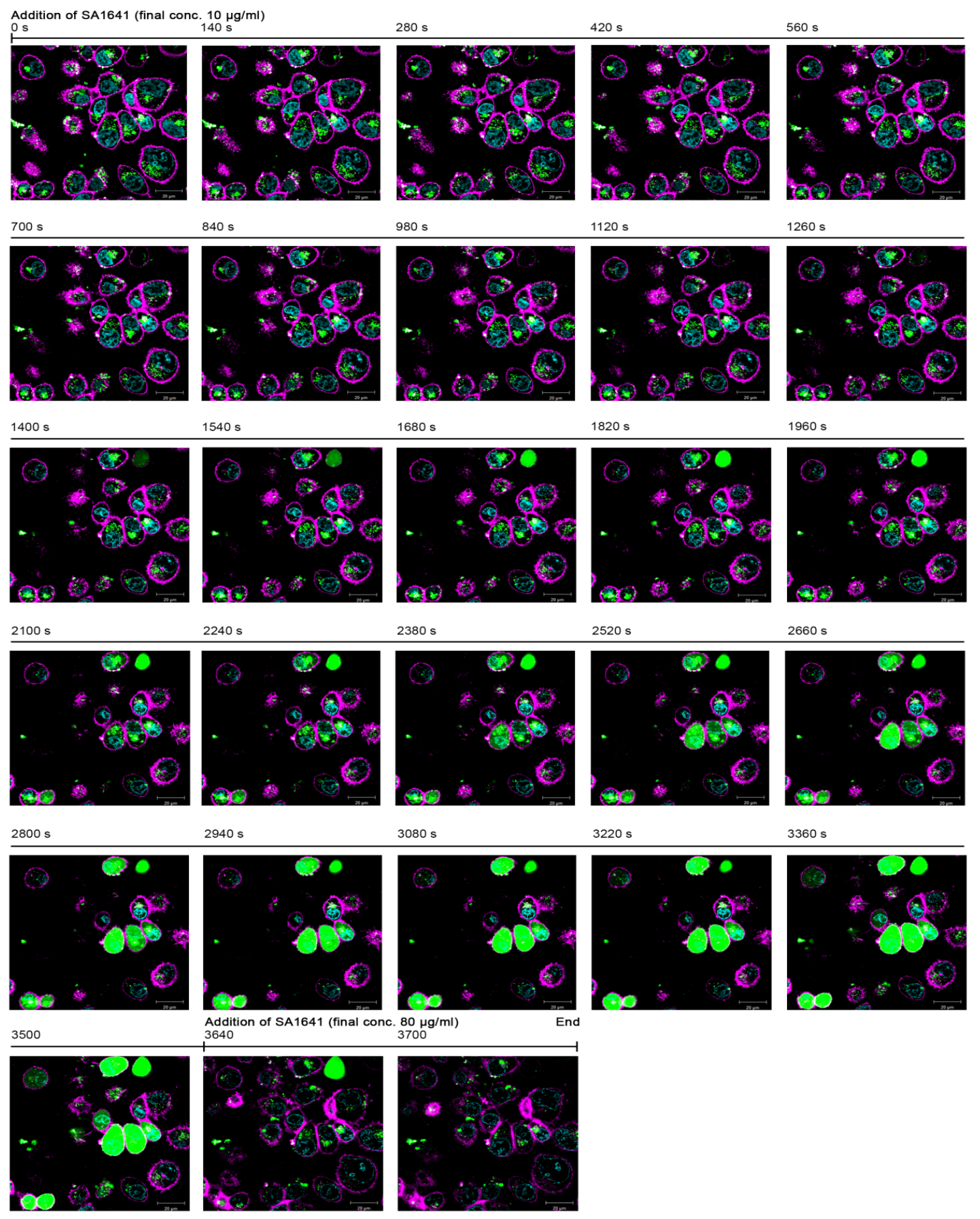


Figure 4. Single endo/lysosome analysis. The endo/lysosomal escape of ${ }^{\text {Alexa }}$ saporin in the presence of SA1641 was monitored in the case of single endo/lysosomes. (A) ECV-304 cells were incubated with ${ }^{\text {Alexa }}$ saporin at $1000 \mathrm{nM}$ and $37{ }^{\circ} \mathrm{C}$ for $3 \mathrm{~h}$, washed, and then, $10 \mu \mathrm{g} / \mathrm{mL}$ SA1641 were added to cells as indicated in Figure 3. ${ }^{\text {Alexa }}$ Saporin is visualized in green fluorescence. A total of 16 single endo/lysosomes was selected and constantly monitored from $\mathrm{t}=2050 \mathrm{~s}$ to $\mathrm{t}=3290 \mathrm{~s}$. For each endo/lysosome, a region of interest (numbered 1-16 in the fluorescence picture) comprised of the surroundings of the endo/lysosomes, but excluding the vesicle itself, was defined; (B) ECV-304 cells were continuously monitored for $7200 \mathrm{~s}$ after the addition of $10 \mu \mathrm{g} / \mathrm{mL}$ of SA1641. Single endo/lysosome analysis is presented as a relation of time (from $\mathrm{t}=2400 \mathrm{~s}$ to $\mathrm{t}=4200 \mathrm{~s}$ ) $v \mathrm{~s}$. the fluorescence intensity of the released Alexa saporin. Each curve represents the fluorescence intensity increase in each region of interest, corresponding to the amount of ${ }^{\text {Alexa }}$ saporin that escapes from each single endo/lysosome.

\section{A}

Single endo/lysosome analysis $2050 \mathrm{~s}$ $2670 \mathrm{~s}$ $3290 \mathrm{~s}$
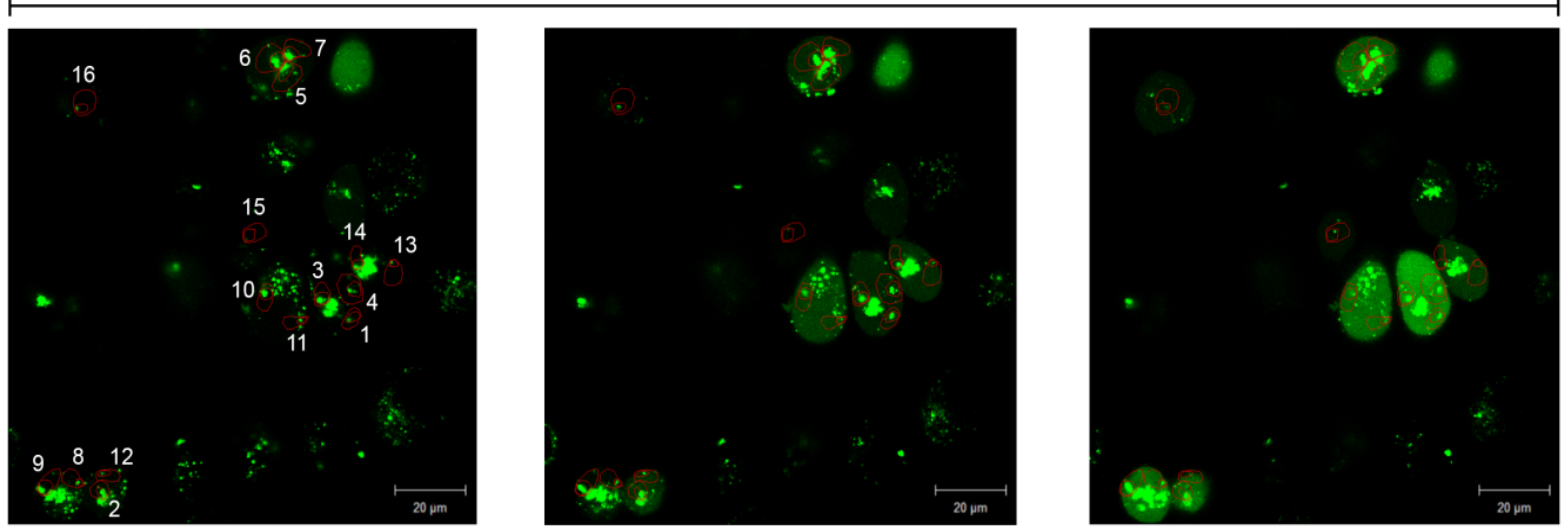

B

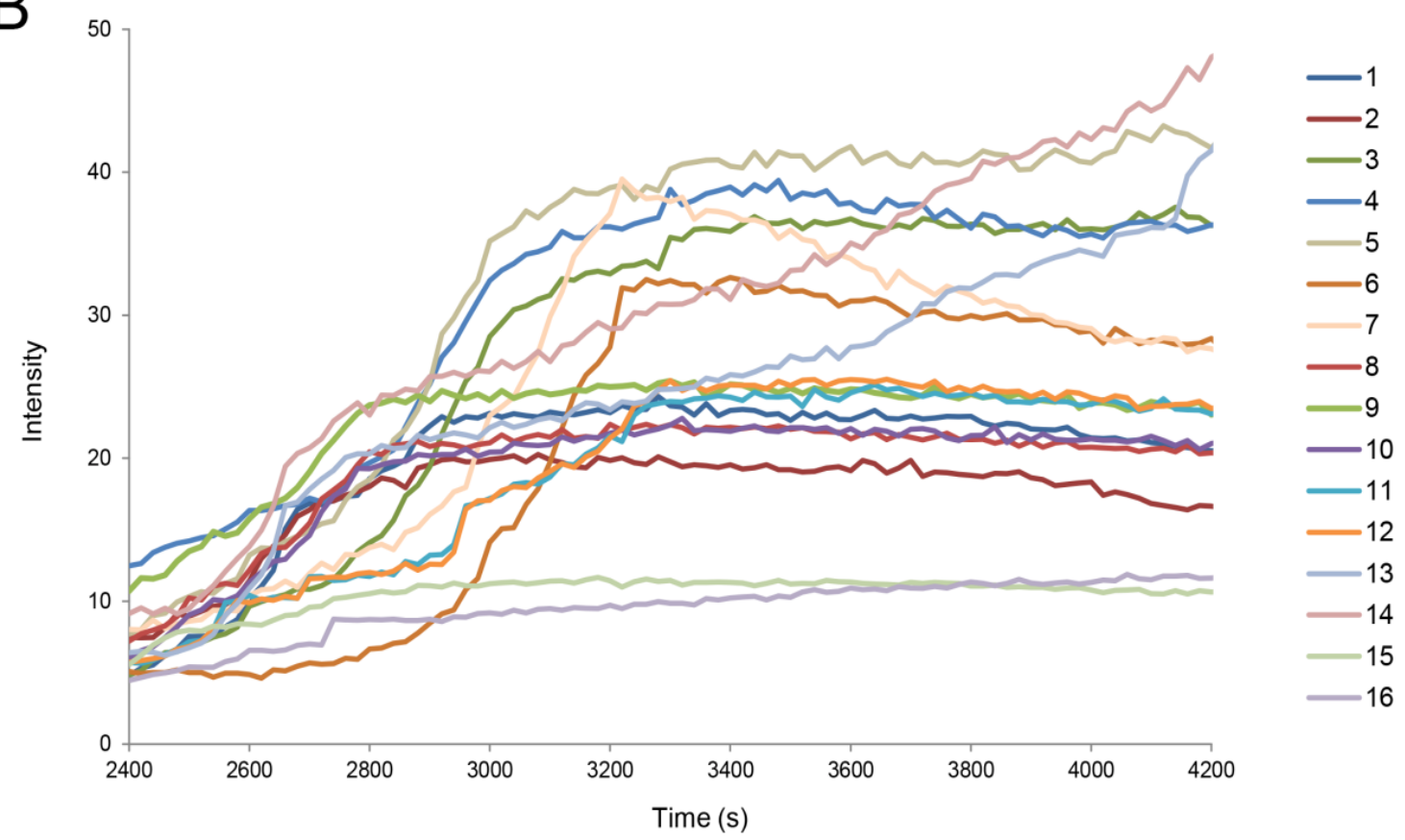


While Figure 1E demonstrates that saporin at $1000 \mathrm{nM}$ in combination with SA1641 produces close to $100 \%$ total cell death, in Figure 3, only a portion of cells treated by saporin at the same concentration in the presence of SA1641 displays the cytosolic fluorescence indicative of the toxin release to the cytosol. This discrepancy may be related to the timing of the experiments and also to the detection limits of the techniques.

Firstly, regarding the timing of the experiments, results presented in Figure 1E refer to cells treated for $48 \mathrm{~h}$, whereas results in Figure 3 represent cells treated first with saporin alone for $3 \mathrm{~h}$ and thereafter with the combination of saporin and SA1641 for $2 \mathrm{~h}$ more. It is therefore expected that a major number of cells will be affected in the first case, since cells have been in contact with both compounds for a longer period of time.

Secondly, concerning the detection limits, the sensitivity of the cytotoxicity assay reaches much lower concentrations than that of confocal microscopy. In Figure 1E, cytotoxicity is observed down to a concentration of $0.1 \mathrm{nM}$. However, the fluorescence diffusion of toxins after endo/lysosomal escape is clearly observed only at $1000 \mathrm{nM}$ (see Figure 3). When an immunotoxin consisting of saporin chemically coupled to the therapeutic antibody, Trastuzumab (Herceptin ${ }^{\circledR}$ ), was labelled with Alexa Fluor 488, its endo/lysosomal escape was also observed at a toxin concentration of $100 \mathrm{nM}$, but the

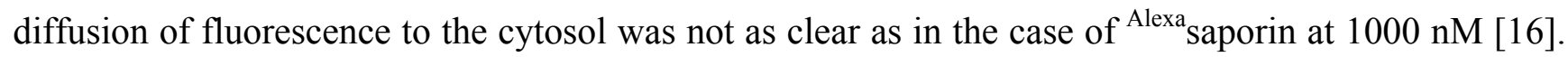
To sum up, the effects of saporin are detected in a major number of cells in the cytotoxicity assay, also probably due to the higher sensitivity of the method.

Alexa Fluor 488 was previously used as a reporter for endo/lysosomal escape of saporin in the presence of triterpenoidal saponins. First, cells were treated with ${ }^{\text {Alexa }}$ saporin in combination with SA1641 [13]. Later, ${ }^{\text {Alexa }}$ saporin was administered to cells in the presence of SO1861 [21]. In both cases, the endo/lysosomal escape of the toxin was observed at a toxin concentration of $1000 \mathrm{nM}$. Based on the previous experiments, the limit of detection with the reporter system for endo/lysosomal escape based on Alexa Fluor 488 is approximated to $100-1000 \mathrm{nM}$. A novelty of the present study is the single endo/lysosome analysis of cells incubated with ${ }^{\text {Alexa }}$ saporin (also at $1000 \mathrm{nM}$ ). To summarize the results of this section, a concentration of $1000 \mathrm{nM}$ was a suitable concentration for single-endo/lysosome analysis and for the usage of Alexa Fluor 488 as a reporter for the endo/lysosomal escape of protein-based therapeutics.

\subsection{Ricin A-Chain As a Reporter}

The third reporter for the endo/lysosomal escape considered in this investigation was the ricin A-chain (RTA). In order to study the usage of RTA as a reporter, it was chemically conjugated to an enzymatically inactive variant of saporin (saporin-KQ), previously reported in the literature [17]. Saporin-KQ was cloned into an expression vector, and the presence of the insert was confirmed by DNA sequencing. Then, saporin-KQ was heterologously expressed and purified by Ni-NTA chromatography (Figure S2A in the Supplementary). The identity of saporin-KQ after recombinant expression and purification was substantiated by Western blot with a primary polyclonal antibody against saporin (Figure S2B, Supplementary). 
After chemical conjugation of saporin-KQ and RTA, a first diffused band with an approximate molecular mass of $60 \mathrm{kDa}$ and a second diffused band with high molecular mass were observed in the reaction mixture by SDS-PAGE (Figure 5A). The first band contained most likely one single saporin-KQ coupled to a single molecule of RTA. In contrast, the second band may probably contain conjugates of saporin-KQ-RTA with different molecular ratios of saporin-KQ conjugated to RTA. Furthermore, a band of approximately $30 \mathrm{kDa}$ was detected, as well, in the reaction mixture, but since saporin-KQ and RTA have a very similar molecular mass, the presence of either one or the other protein cannot be distinguished.

To purify the saporin-KQ-RTA conjugates from the unconjugated saporin-KQ and unconjugated RTA, Ni-NTA chromatography was carried out, and all the fractions were analysed by SDS-PAGE (Figure 5B). On the one hand, unconjugated RTA was directly eluted in the flow-through, as it lacks the $6 \times$ his-tag. On the other hand, unconjugated saporin-KQ (presenting the $6 \times$ his-tag) was eluted in Fractions $1-5$ at $62 \mathrm{mM}$ and $1-2$ at $125 \mathrm{mM}$ imidazole. In the case of saporin-KQ-RTA (also presenting the $6 \times$ his-tag), the conjugate was eluted in Fractions 5 at $125 \mathrm{mM}$ and $1-5$ at $250 \mathrm{mM}$ imidazole. All fractions that contained the purified conjugate were pooled together, desalted and concentrated. The final amount of saporin-KQ-RTA was $0.26 \mathrm{mg}$ of conjugate, and the relative yield of the chemical conjugation and subsequent purification was $18 \%$ of protein input (saporin-KQ plus RTA).

In order to check that saporin-KQ was enzymatically inactive, the $N$-glycosidase activity of saporin was compared to that of saporin-KQ. In the case of saporin, the release of adenine after incubation with herring sperm DNA was $117.6 \mathrm{pmol}$ adenine/pmol toxin/h (see Section 2.1). However, in the case of saporin-KQ, no adenine release was observed after the incubation of the inactive mutant with the substrate. In brief, the enzymatic inactivity of saporin-KQ was confirmed.

The effect of triterpenoidal saponins ( $\mathrm{SO} 1861$ at $1-2 \mu \mathrm{g} / \mathrm{mL}$ ) on the enhancement of the endo/lysosomal escape of saporin-KQ was compared to that on saporin and RTA. Saporin alone presented cytotoxicity at a concentration of $100 \mathrm{nM}$ and reduced the viability to $76 \%$ (Figure 5C). In combination with SO1861, the cytotoxicity of saporin was tremendously augmented, and cell viability was reduced to $53 \%$ at a concentration of $0.1 \mathrm{nM}$. These results are comparable to those obtained for the combination of saporin and SA1641 in Figure 1E. Both triterpenoidal saponins (SA1641 and SO1861) have been reported for the specific enhancement of the endo/lysosomal escape of saporin (SA1641 in [13] and SO1861 in [21]), and in both cases, this phenomenon has been elucidated by cytotoxicity assays, as well as by confocal microscopy. The endo/lysosomal escape of saporin mediated by both triterpenoidal saponins is consequently based on the same molecular mechanism, and this allows the comparison between the different reporters presented in this study.

In the case of RTA (Figure 5D), the toxin alone was already very cytotoxic at 1 and $10 \mathrm{nM}$ (cell viability of $31 \%$ and $14 \%$, respectively). RTA at a final concentration of $0.1 \mathrm{nM}$ was also cytotoxic, and cell viability was reduced to $73 \%$. When RTA was applied in combination with SO1861, the toxin presented very similar cytotoxic effects as before with no significant differences. The drastic cytotoxicity augmentation of saporin in the presence of triterpenoidal saponins was not observed for RTA. These results are in accordance with the literature that indicates that SO1861 specifically modulates the intracellular trafficking of saporin [13] and that RTA and saporin follow different intracellular routes to enter the cytosol [22]. 
Figure 5. Ricin A-chain (RTA) as a reporter for endo/lysosomal escape. The report of the endo/lysosomal escape enhancement of saporin-KQ (an enzymatically inactive saporin in order to avoid interferences in the readout of the experiment) was attempted by measuring the cytotoxic activity of RTA. (A) Saporin-KQ and RTA were chemically cross-linked. The reaction mixture was analysed by SDS-PAGE, and both unconjugated saporin-KQ and RTA were included as controls; (B) Saporin-KQ-RTA was purified by Ni-NTA chromatography. Proteins were eluted with increasing concentrations of imidazole $(31,62,125$ and $250 \mathrm{mM})$, and an SDS-PAGE analysis was effectuated for the fractions. Saporin-KQ-RTA was eluted in Fractions 5 at $125 \mathrm{mM}$ and $1-5$ at $250 \mathrm{mM}$ imidazole (see arrows); Cytotoxicity of (C) saporin; (D) RTA; (E) saporin-KQ; and (F) saporin-KQ-RTA in combination with SO1861. ECV-304 (4000 cells/well) were treated with saporin, RTA, saporin-KQ or saporin-KQ-RTA in a concentration range from 0.01 to $1000 \mathrm{nM}$ in the presence or absence of SO1861 (final concentration of $1-2 \mu \mathrm{g} / \mathrm{mL}$ ) for $48 \mathrm{~h}$. The viability of cells was evaluated by the MTT assay. Data is the mean $\pm \mathrm{SD}, n=4$.
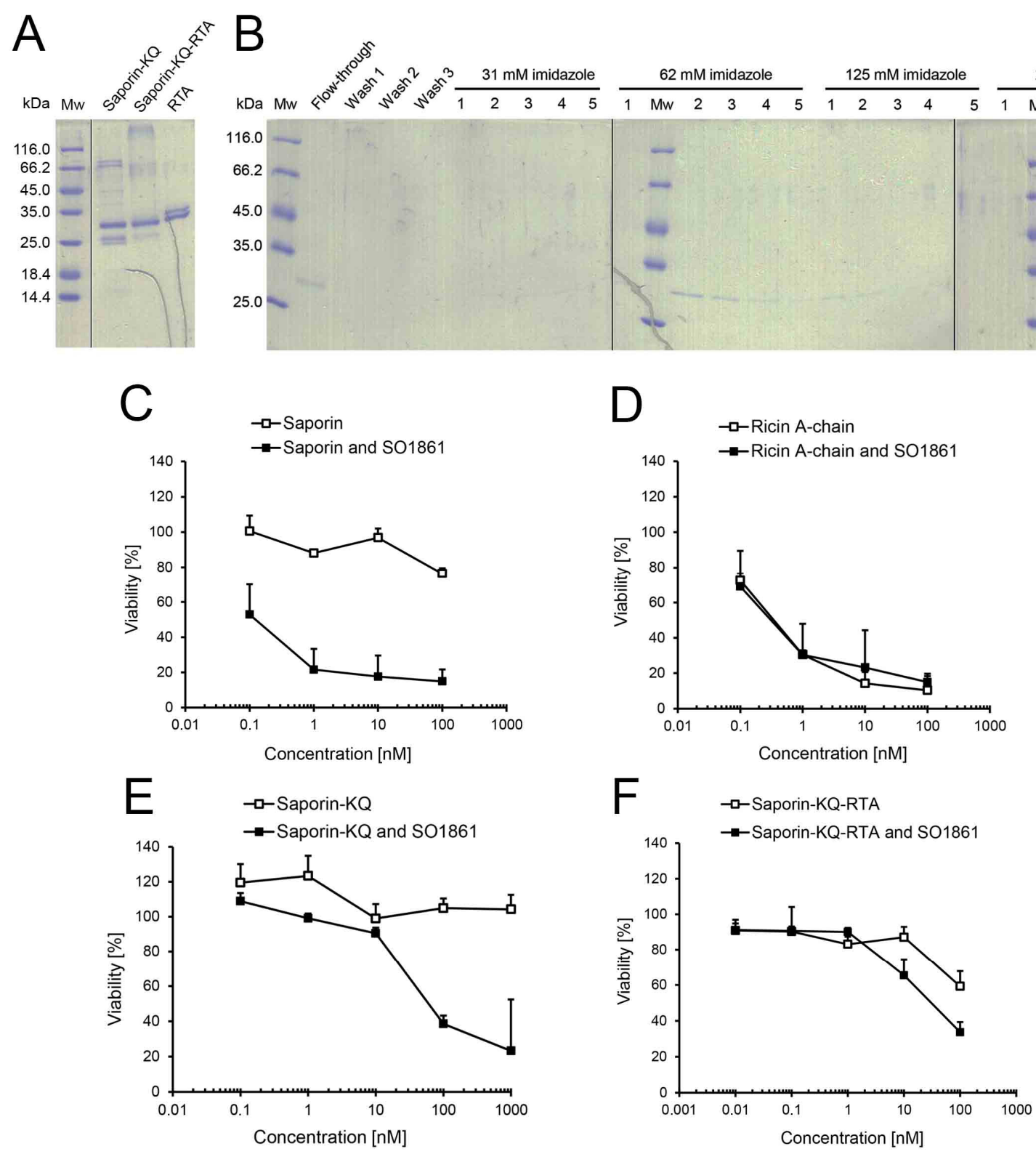
The cytotoxicity of saporin-KQ was also evaluated alone or in combination with SO1861 to assure that the enzymatically inactive saporin was non-cytotoxic (Figure 5E). According to its mutation, which turns saporin-KQ into an enzymatically inactive protein, saporin-KQ did not present any cytotoxicity up to $1000 \mathrm{nM}$. Nevertheless, in the presence of SO1861, saporin-KQ caused the inhibition of cell growth at the two highest concentrations tested (presumably due to known mechanisms unrelated to enzymatic activity; see below), and cell viability was reduced to $39 \%$ $(100 \mathrm{nM})$ and 23\% (1000 nM), indicating an endo/lysosomal escape enhancement of saporin-KQ in the presence of triterpenoidal saponins. As cells cannot be killed by the enzymatic activity of saporin-KQ (inactive mutant), it is hypothesized that saporin-KQ induces caspase-dependent apoptosis via the mitochondrial or intrinsic pathway, independently of translation inhibition [23].

Finally, the cytotoxicity of saporin-KQ-RTA was evaluated in the presence of SO1861 to find out whether the endo/lysosomal escape of saporin-KQ was efficiently reported by RTA (Figure 5F). When saporin-KQ-RTA was tested alone, it was cytotoxic only at the highest concentration tested (100 nM), reducing cell viability to $59 \%$. In contrast, in the presence of SO1861, saporin-KQ-RTA was cytotoxic already at a concentration of $10 \mathrm{nM}$ lowering cell viability to $65 \%$ and also at $100 \mathrm{nM}$, decreasing cell viability to $34 \%$. Remarkably, the cytotoxicity of saporin-KQ-RTA was enhanced in the presence of triterpenoidal saponins. Considering that the cytotoxicity of the reporter RTA is not enhanced by SO1861 (see Figure 5D) and that the cytotoxic effects of saporin-KQ in the presence of SO1861 only appear with concentrations higher than $100 \mathrm{nM}$ (see also Figure 5E), the cytotoxicity enhancement of saporin-KQ-RTA at $10 \mathrm{nM}$ mediated by SO1861 can only be explained by the endo/lysosomal escape enhancement of the saporin-KQ moiety and the cytotoxicity of the RTA reporter once the conjugate has reached the cytosol. Thus, the reporter assay based on RTA was able to detect the endo/lysosomal escape with a sensitivity down to $10 \mathrm{nM}$.

Theoretically, since it has been reported that the presence of a single molecule of ricin in the cytosol is enough to trigger apoptosis and thus kill a cell [24], the strategy of using RTA as a reporter would allow the achievement of sensitivities even lower than $10 \mathrm{nM}$. From the present investigations, it can be certainly concluded that RTA is only an appropriate reporter for protein therapeutics affected by structurally-specific triterpenoidal saponins. However, we hypothesize that RTA could be further used as an endo/lysosomal escape reporter for protein therapeutics that are affected by compounds (endo/lysosomal escape enhancers) that do not cause any effects on RTA and for proteins therapeutics that achieve the endo/lysosomal escape in concentrations lower than the cytotoxicity of RTA alone $(<0.1 \mathrm{nM}$, see Figure 5D). This methodology confers the possibility of detecting small quantitative differences, which only take place at very low concentrations, in the endo/lysosomal escape of a protein-based therapeutic under different conditions.

\section{Experimental Section}

\subsection{Molecular Cloning of Saporin and Saporin-KQ}

The plasmid codifying for saporin (6× his-tagged-saporin-pET11d) was cloned in previous studies [25]. The DNA for saporin-KQ previously reported in the literature [17] was synthesized and cloned into the pEN08H vector (6× his-tagged-saporin-KQ-pEN08H) by Entelechon (Regensburg, 
Germany). To insert the DNA for saporin-KQ in the expression vector, pET11d (Novabiochem, Schwalbach, Germany), the $6 \times$ his-tagged-saporin-KQ-pEN08H and $6 \times$ his-tagged-dianthin-30- epidermal growth factor-pET11d [26] were digested by NcoI and EcoRI-HF (New England Biolabs, Ipswich, MA, USA). The digested DNA for saporin-KQ and the digested vector pET11d were separated from the other digestion products by agarose gel electrophoresis, and appropriate DNA bands were extracted with the Zymoclean Gel DNA Recovery Kit (Zymo Research, Irvine, CA, USA). The concentration of the extracted digested products was determined by the Nanodrop ND-1000 Spectrophotometer (Peqlab, Erlangen, Germany). Insert and vector (molar ratio of 3:1) were ligated by T4 DNA ligase (New England Biolabs, Ipswich, MA, USA). The resulting plasmid 6× his-tagged-saporin-KQ-pET11d was transformed and propagated in Escherichia coli Library Efficiency DH5a Competent Cells (Life Technologies, Carlsbad, CA, USA). The plasmid was extracted by the Zyppy Plasmid Miniprep Kit (Zymo Research, Irvine, CA, USA). The DNA sequence for saporin-KQ was sequenced by the method of BigDye Terminator Sequencing (Applied Biosystems, Carlsbad, CA, USA) using a forward primer binding at the $\mathrm{T} 7$ promoter, at the 5'-end of the insert (5'-TAATACGACTCACTATAG-3'), and a reverse primer binding at the pET11d vector, at the 3'-end of the insert (5'-CCTGACGTCTAAGAAACC-3'). Samples were sequenced with the ABI PRISM 310 Genetic Analyser (Advanced Biolab Service, München, Germany).

\subsection{Heterologous Expression of Recombinant Proteins}

The plasmids coding for saporin (6× his-tagged-saporin-pET11d) or saporin-KQ (6× his-tagged-saporin-KQ-pET11d) were transformed into Escherichia coli Rosetta 2(DE3) pLysS Competent Cells (Novagen, San Diego, CA, USA). The proteins were expressed as described elsewhere [27]. In short, the bacteria comprising the corresponding plasmid were grown up to a culture of $2 \mathrm{~L}$, until an optical density $\mathrm{A}_{600 \mathrm{~nm}}=0.9$, and protein expression was induced by the addition of isopropyl $\beta$-D-1-thiogalactopyranoside (IPTG) (final concentration of $1 \mathrm{mM}$ ). Protein expression was allowed for $3 \mathrm{~h}$ at $37{ }^{\circ} \mathrm{C}$. Thereafter, the bacterial suspension was centrifuged, pellets were re-suspended in phosphate-buffered saline (PBS) and stored at $-20^{\circ} \mathrm{C}$ until further use.

\subsection{Chemical Conjugation of Reporters to Saporin}

Saporin (see Section 3.4 for its purification) was chemically conjugated to the reporter HRP (Serva Electrophoresis, Heidelberg, Germany) via modification of the $N$-glycans of HRP by sodium periodate $\left(\mathrm{NaIO}_{4}\right)$ oxidation and sodium borohydride $\left(\mathrm{NaBH}_{4}\right)$ reduction. Freshly prepared $0.1 \mathrm{M} \mathrm{NaIO}$ $(185.05 \mu \mathrm{L}$ ) was added to $7.30 \mathrm{mg}$ HRP (previously dissolved in $2 \mathrm{~mL}$ water), and the solution was stirred for $20 \mathrm{~min}$ at room temperature protecting it from light. The modified HRP was dialyzed overnight at $4{ }^{\circ} \mathrm{C}$ against $8 \mathrm{~L}$ of $1 \mathrm{mM}$ sodium acetate buffer $(\mathrm{pH} 4.4)$. In parallel, $2 \mathrm{~mL}$ saporin $(1.235 \mathrm{mg} / \mathrm{mL})$ was buffered with $200 \mu \mathrm{L}$ sodium hydrogen carbonate buffer $(0.2 \mathrm{M}, \mathrm{pH} 9.5)$. The $\mathrm{pH}$ value of the dialyzed modified HRP was adjusted to $9.0-9.5$ by adding $80 \mu \mathrm{L}$ sodium hydrogen carbonate buffer, and it was immediately mixed with the saporin solution (molar ratio of 2:1 for HRP:saporin). The mixture was stirred for $2 \mathrm{~h}$ at room temperature. After the incubation time, $100 \mu \mathrm{L}$ of freshly prepared $\mathrm{NaBH}_{4}(4 \mathrm{mg} / \mathrm{mL})$ was added to the mixture, and it was further stirred for $2 \mathrm{~h}$ at 4 
${ }^{\circ} \mathrm{C}$. The protein solution was dialyzed overnight against 2 L PBS. The saporin-HRP solution was further purified by Ni-NTA affinity chromatography.

Saporin was conjugated to the reporter Alexa Fluor 488 carboxylic acid, 2,3,5,6-tetrafluorophenyl ester (Alexa Fluor 488 5-TFP) (Molecular Probes, Eugene, USA), by adding $100 \mu \mathrm{L}$ sodium hydrogen carbonate buffer (1 M, pH 9.0) and $100 \mu \mathrm{L}$ of Alexa Fluor 4885 -TFP ( $5 \mathrm{mg} / \mathrm{mL}$ in DMSO) to $750 \mu \mathrm{L}$ of saporin $(1.2 \mathrm{mg} / \mathrm{mL}$ in PBS). The samples were cross-linked for $1 \mathrm{~h}$ at room temperature and then dialyzed overnight at $4{ }^{\circ} \mathrm{C}$ against $2 \mathrm{~L}$ PBS to purify the conjugate ${ }^{\text {Alexa }}$ saporin from unconjugated Alexa Fluor 488 5-TFP.

Saporin-KQ (details for purification in Section 3.4) was chemically conjugated to the reporter RTA (buffered aqueous glycerol solution, Sigma-Aldrich, Steinheim, Germany) by the same chemical procedure described before in the case of the saporin-HRP conjugate. Freshly prepared $0.1 \mathrm{M} \mathrm{NaIO}_{4}$ $(185.05 \mu \mathrm{L})$ was added to $2.30 \mathrm{mg}$ RTA (previously dialyzed in water and diluted to a volume of $2.85 \mathrm{~mL}$ ). After the overnight dialysis of the modified RTA against sodium acetate buffer, $400 \mu \mathrm{L}$ sodium hydrogen carbonate buffer was added to $2 \mathrm{~mL}$ saporin-KQ $(0.250 \mathrm{mg} / \mathrm{mL})$. Subsequently, $400 \mu \mathrm{L}$ sodium hydrogen carbonate buffer was added to the RTA solution, and it was immediately mixed with the saporin-KQ solution (molar ratio of 2:1 for RTA:saporin-KQ). The chemical conjugation was finished by the addition of freshly prepared $\mathrm{NaBH}_{4}(100 \mu \mathrm{L}, 4 \mathrm{mg} / \mathrm{mL})$, the incubation of the mixture and overnight dialysis in PBS. Saporin-KQ-RTA solution was also purified by Ni-NTA affinity chromatography.

\subsection{Purification of Proteins and Conjugates}

After heterologous expression of recombinant proteins, bacterial suspensions containing saporin or saporin-KQ were thawed on ice, and bacteria lysis was achieved by sonication (G. Heinemann, Schwäbisch Gmünd, Germany). Bacteria debris was separated by centrifugation at $15,800 \times g$ and $4{ }^{\circ} \mathrm{C}$ for $30 \mathrm{~min}$, and after the addition of imidazole (final concentration of $20 \mathrm{mM}$ ), recombinant proteins were purified from the supernatants by Ni-nitrilotriacetic acid (NTA) agarose affinity chromatography (Protino Ni-NTA agarose, Macherey-Nagel, Düren, Germany). Ni-NTA agarose (1.5-2.0 $\mathrm{mL}$ ) was added to the supernatants or the conjugate solutions (saporin-HRP and saporin-KQ-RTA, see Section 3.3) and the $6 \times$ his-tagged proteins bound to the matrix under continuous shaking during $30 \mathrm{~min}$ at $4{ }^{\circ} \mathrm{C}$. The affinity chromatography was initiated after pouring the matrix with the bound proteins into a $20-\mathrm{mL}$ column (Econo-Pac chromatography columns, Bio-Rad, Hercules, CA, USA). The column was washed three times with $10 \mathrm{~mL}$ wash buffer (50 mM $\mathrm{NaH}_{2} \mathrm{PO}_{4}, 300 \mathrm{mM} \mathrm{NaCl}, 20 \mathrm{mM}$ imidazole), and the $6 \times$ his-tagged proteins were eluted with increasing concentrations of imidazole $(31,62,125$ and $250 \mathrm{mM})$ in wash buffer. In total, 5 fractions of $2 \mathrm{~mL}$ per each concentration were collected. Flow-through, washes and each of the fractions were analysed by SDS-PAGE $(12 \%(w / v)$ gel). Fractions containing the protein of interest were pooled and dialyzed overnight at $4{ }^{\circ} \mathrm{C}$ against $2 \mathrm{~L}$ PBS. The desalted protein was concentrated via centrifugation with an Amicon Ultra-15 10,000 NMWL (Merck Millipore, Carrigtwohill, Ireland), and the protein concentration was finally determined by a bicinchoninic acid (BCA) assay (Pierce/Thermo Scientific, Waltham, MA, USA). 


\subsection{Identity Validation of Recombinant Proteins and Conjugates}

To validate the identity of recombinantly expressed saporin and saporin-KQ, the proteins were analysed by western blot with a primary self-raised rabbit polyclonal antibody against saporin (1:300 diluted). Polyclonal goat anti-rabbit immunoglobulins/horseradish peroxidase (1:10,000 diluted) (P0448, Dako Cytomation, Hamburg, Germany) was used as secondary antibody, and its presence was detected by the enhanced chemiluminescence reaction. After exposure, the photographic paper (Amersham Hyperfilm ECL, GE Healthcare, Uppsala, Sweden) was developed by an Optimax X-Ray Film Processor (Protec Medizintechnik, Oberstenfeld, Germany). The validation of the chemical conjugation of saporin and HRP was effectuated following the same methodology.

\subsection{Characterization of Peroxidase and N-Glycosidase Activity}

The peroxidase activity of saporin-HRP was measured by adding $100 \mu \mathrm{L}$ of the conjugate (concentrations from 0.00001 to $100 \mathrm{nM}$ ) to $100 \mu \mathrm{L}$ of reagent $(80 \mathrm{mM}$ citric acid, $0.4 \mathrm{mg} / \mathrm{mL}$ 3,3',5,5'-tetramethylbenzidine, $0.2 \mu \mathrm{g} / \mathrm{mL} \mathrm{H}_{2} \mathrm{O}_{2}, \mathrm{pH} 3.95$ ). The mixture was incubated for $15 \mathrm{~min}$ at room temperature. The reaction was stopped by the addition of $50 \mu \mathrm{L} \mathrm{H}_{2} \mathrm{SO}_{4}(3.3 \mathrm{M})$, and the absorbance of the mixture was measured at $450 \mathrm{~nm}$ (reference at $490 \mathrm{~nm}$ ) by a SpectraMax 340PC Absorbance Microplate Reader (Molecular Devices, Sunnyvale, CA, USA).

The procedure for the determination of peroxidase activity was modified to record the peroxidase activity of saporin-HRP in cellular fractions (see Section 3.8). Either $50 \mu \mathrm{L}$ of the (1) cytosolic fraction or (2) lysosomal fraction were added to $20 \mu \mathrm{L}$ citrate buffer (80 mM citric acid, $\mathrm{pH} 3.95)$. After incubation of the fractions for $5 \mathrm{~min}$, the precipitate was discarded by centrifugation at $16,100 \times g$ for $2 \mathrm{~min}$. Then, $50 \mu \mathrm{L}$ of the reagent were added to the supernatant. The mixture was incubated for $1 \mathrm{~h}$ at room temperature, and the reaction was stopped by adding $50 \mu \mathrm{L} \mathrm{H}_{2} \mathrm{SO}_{4}(3.3 \mathrm{M})$.

To measure the activity of saporin-HRP released from isolated lysosomes, the protein solution (20 $\mu \mathrm{L}$ of supernatant after the last centrifugation step; see Section 3.8) was mixed first with $30 \mu \mathrm{L}$ translocation buffer (20 mM HEPES, $10 \mathrm{mM} \mathrm{MgSO}_{4}$ and $0.1 \mathrm{M} \mathrm{KCl}, \mathrm{pH} 7.0$ ). Thereafter, $50 \mu \mathrm{L}$ of reagent were added, and the mixture was incubated for $1 \mathrm{~h}$ at room temperature. The reaction was stopped by adding $25 \mu \mathrm{L} \mathrm{H}_{2} \mathrm{SO}_{4}(3.3 \mathrm{M})$.

The $N$-glycosidase activity of proteins was determined by the cleavage and release of adenine residues from herring sperm DNA [26,28]. First, a standard curve was prepared with adenine by measuring the absorbance at $260 \mathrm{~nm}$ (reference at $300 \mathrm{~nm}$ ) for concentrations of 10, 20, 40, 80, 160 and $320 \mathrm{pmol} / \mu \mathrm{L}$ adenine. Absorbance was measured by the Nanodrop ND-1000 Spectrophotometer.

To determine the $N$-glycosidase activity of saporin-HRP and saporin-KQ, $10 \mu \mathrm{L}$ herring sperm DNA (100 $\mu \mathrm{g})$ (Invitrogen, Darmstadt, Germany) was added to $30 \mathrm{pmol}$ saporin (control), saporin-HRP or saporin-KQ and acetate buffer $\left(50 \mathrm{mM} \mathrm{CH} \mathrm{COONa}_{3} 100 \mathrm{mM} \mathrm{KCl}, \mathrm{pH} 5.0\right)$ up to $50 \mu \mathrm{L}$. The mixture was incubated under continuous shaking at $50{ }^{\circ} \mathrm{C}$ for $1 \mathrm{~h}$. Thereafter, the mixture was transferred to a filtration device (MWCO 3000 Da) (Millipore, Billerica, MA, USA) and centrifuged at $4{ }^{\circ} \mathrm{C}$ and $5000 \times \mathrm{g}$ for $45 \mathrm{~min}$. The absorbance of the filtrate was measured at $260 \mathrm{~nm}$ (reference at $300 \mathrm{~nm}$ ). 


\subsection{Cytotoxicity Assays}

ECV-304 cells (human urinary bladder carcinoma cell line) (ACC 310, Deutsche Sammlung von Mikroorganismen und Zellkulturen, Braunschweig, Germany) were cultured in Dulbecco's modified Eagle's medium (DMEM) (PAA Laboratories, Pasching, Austria) supplemented with 10\% foetal bovine serum (FBS) (BioChrom KG, Berlin, Germany) and 1\% penicillin/streptomycin (PS) (Gibco/Invitrogen, Karlsruhe, Germany).

The cytotoxicity of the combination of SA1641 (purified by HPLC as indicated in [29]) with saporin or saporin-HRP was evaluated by first adding $100 \mu \mathrm{L} /$ well of DMEM supplemented with $10 \%$ FBS and 1\% PS containing 4000 ECV-304 cells into a 96-well plate. Cells were allowed to grow for $24 \mathrm{~h}$, and thereafter, the medium was removed. Then, $180 \mu \mathrm{L} /$ well fresh medium or medium containing SA1641 (final concentration of $5 \mu \mathrm{g} / \mathrm{mL}$ ) and $20 \mu \mathrm{L} /$ well PBS containing either saporin or saporin-HRP (final concentrations from 0.01 to $100 \mathrm{nM}$ ) were added, and cells were incubated for a further $48 \mathrm{~h}$. Cells treated with $180 \mu \mathrm{L} /$ well fresh medium and only $20 \mu \mathrm{L} /$ well PBS served as the control. To determine the cytotoxicity of the combination of SO1861 (isolated by HPLC as described in [15]) with saporin, RTA, saporin-KQ or saporin-KQ-RTA, $180 \mu \mathrm{L} /$ well medium containing SO1861 (final concentration of $1-2 \mu \mathrm{g} / \mathrm{mL}$ ) and $20 \mu \mathrm{L} /$ well PBS containing saporin, RTA, saporin-KQ or saporin-KQ-RTA (final concentrations from 0.01 to $1000 \mathrm{nM}$ ) were added.

To measure the degree of cell proliferation after the treatment of cells under the different conditions, the final viable cell number was determined by the 3-(4,5-dimethylthiazol-2-yl)-2,5-diphenyltetrazolium bromide (MTT) assay. A solution of MTT $(5 \mathrm{mg} / \mathrm{mL}, 30 \mu \mathrm{L} /$ well $)$ was pipetted directly to the media. The plate was incubated at $37^{\circ} \mathrm{C}$ for $2 \mathrm{~h}$, and thereafter, the media containing MTT was removed. A formazan solubilizer $(50 \mu \mathrm{L} /$ well) consisting of $82 \%(v / v)$ isopropanol (pure), $10 \%(v / v)$ of SDS solution $(10 \%(w / v))$ and $8 \%(v / v)$ of $\mathrm{HCl}$ solution $(1 \mathrm{M})$ was added to the plate, and after shaking it for $5 \mathrm{~min}$, the absorbance was measured at $570 \mathrm{~nm}$ (reference at $630 \mathrm{~nm}$ ) by the SpectraMax 340PC Absorbance Microplate Reader. All percentages of cell survival were calculated referring to the control.

\subsection{Cell Fractionation, Isolation and Characterization of Lysosomes}

For the evaluation of the endo/lysosomal escape of saporin-HRP via cellular fractionation of cells previously treated with the same conjugate in the presence of SA1641, ECV-304 cells were seeded in $75-\mathrm{cm}^{2}$ dishes and grown to confluence in DMEM supplemented with $10 \%$ FBS and $1 \%$ PS. Cells of 4 dishes $\left(1.5 \times 10^{7}\right.$ cells $)$ were treated with $2 \mathrm{~mL}$ saporin-HRP $(100 \mathrm{nM}$ in medium $)$ in the presence or absence of SA1641 (final concentration of $5 \mu \mathrm{g} / \mathrm{mL}$ ) at $37^{\circ} \mathrm{C}$ for $6 \mathrm{~h}$. Cells were washed 3 times with $2 \mathrm{~mL}$ ice-cold PBS. Subsequently, $1 \mathrm{~mL}$ ice-cold PBS was added, and cells were scraped (Falcon Cell Scraper, Fisher Scientific/Thermo Scientific, Waltham, MA, USA) from the cell culture dishes. Furthermore, $1 \mathrm{~mL}$ ice-cold PBS supplemented with protease inhibitor Complete (Roche Applied Science, Mannheim, Germany) was added to re-suspended cells. Cells were loaded into a 2-mL cell homogenizer with a small clearance pestle (Sigma-Aldrich, Steinheim, Germany) and homogenized in 28 cycles. Initially, the homogenate was centrifuged at $1000 \times \mathrm{g}$ for $10 \mathrm{~min}$ at $4{ }^{\circ} \mathrm{C}$. Then, the pellet was discarded, and the supernatant was further centrifuged at $100,000 \times g$ and $4{ }^{\circ} \mathrm{C}$ for $1 \mathrm{~h}$ with the Optima L-90K Ultracentrifuge (Beckman Coulter, Krefeld, Germany). After ultracentrifugation, the 
supernatant corresponded to the (1) cytosolic fraction, while the pellet contained all cellular organelles, including the lysosomes. The pellet was re-suspended, frozen and thawed 5 times in order to disrupt the lysosomal membranes and centrifuged again at $100,000 \times g$ and $4{ }^{\circ} \mathrm{C}$ for $1 \mathrm{~h}$. After this second ultracentrifugation step, the supernatant corresponded to the (2) lysosomal fraction. The presence of saporin-HRP in both the (1) cytosolic fraction and (2) lysosomal fraction was analysed by the determination of peroxidase activity (see Section 3.6).

For the isolation of lysosomes to further characterize the endo/lysosomal escape of saporin-HRP in isolated organelles, eight $75-\mathrm{cm}^{2}$ dishes with ECV-304 cells were allowed to proliferate to confluence $\left(3 \times 10^{7}\right.$ cells) in DMEM supplemented with $10 \%$ FBS and $1 \%$ PS. After a washing step with PBS, cells were detached using $0.25 \%$ Trypsin-EDTA. Re-suspended cells were centrifuged for 5 min at $800 \times g$ and $4{ }^{\circ} \mathrm{C}$ and washed with $10 \mathrm{~mL}$ ice-cold PBS. Cells were centrifuged and washed one more time and finally re-suspended in $6 \mathrm{~mL}$ ice-cold PBS. Cells were homogenized in 28 cycles by a 7-mL cell homogenizer with a small clearance pestle (Sigma-Aldrich, Steinheim, Germany). To achieve a crude fraction rich in lysosomes, the homogenate was submitted to differential centrifugation at $1000 \times g$ for $10 \mathrm{~min}$ at $4{ }^{\circ} \mathrm{C}$ and the corresponding supernatant at $20,000 \times g$ for $20 \mathrm{~min}$. Ice-cold translocation buffer $(400 \mu \mathrm{L})\left(20 \mathrm{mM}\right.$ HEPES, $10 \mathrm{mM} \mathrm{MgSO}_{4}$ and $\left.0.1 \mathrm{M} \mathrm{KCl}, \mathrm{pH} 7.0\right)$ supplemented with $2 \mathrm{mM}$ adenosine triphosphate (ATP) was added to the pellet (obtained after centrifugation at $20,000 \times g$ ) that contained the lysosomes. The crude lysosomal fraction was stored at $4{ }^{\circ} \mathrm{C}$.

Firstly, the permeabilizing effects of digitonin (Ysat, Wernigerode, Germany), $\alpha$-hederin (Sigma-Aldrich, Steinheim, Germany) and SA1641 were measured on lysosomal membranes by the $\beta$ - $N$-acetylglucosaminidase (NAG) assay [30]. The crude lysosomal fractions were shortly centrifuged at $1000 \times g$ for $2 \mathrm{~min}$ at $4{ }^{\circ} \mathrm{C}$ to discard the aggregated organelles. Then, $5 \mu \mathrm{L}$ of the crude lysosomal fraction was treated with $45 \mu \mathrm{L}$ translocation buffer in the presence of digitonin, $\alpha$-hederin or SA1641 at the final concentrations of $0.05,0.5,5,10$ and $50 \mu \mathrm{M}$ at $37{ }^{\circ} \mathrm{C}$ for $1 \mathrm{~h}$. To determine the amount of lysosomal enzyme NAG released from the lysosomes under these conditions, the lysosomes were centrifuged at $20,000 \times g$ for $20 \mathrm{~min}$, and $\beta-N$-acetylglucosaminidase activity in the supernatant $(10 \mu \mathrm{L})$ was evaluated by the addition of a substrate solution $(90 \mu \mathrm{L})(0.09 \mathrm{M}$ citrate buffer, $1 \mathrm{mg} / \mathrm{mL}$ 4-nitrophenyl $N$-acetyl- $\beta$-D-glucosaminide, $\mathrm{pH} 4$.7) previously equilibrated at $37^{\circ} \mathrm{C}$. The reaction was incubated at $37{ }^{\circ} \mathrm{C}$ for $10 \mathrm{~min}$, and after the addition of $200 \mu \mathrm{L} \mathrm{Na}_{2} \mathrm{CO}_{3}(0.4 \mathrm{M})$, the absorbance was measured at $405 \mathrm{~nm}$ by the SpectraMax 340PC Absorbance Microplate Reader.

Secondly, for the evaluation of the endo/lysosomal escape of saporin-HRP in isolated lysosomes from cells previously treated with the same conjugate, ECV-304 cells were incubated with medium containing saporin-HRP $(100 \mathrm{nM})$. After $6 \mathrm{~h}$ of the addition of the compound, cells were washed with PBS, and the detachment of cells was initiated by the addition of $0.25 \%$ Trypsin-EDTA. The procedure to isolate the lysosomes (in this case, loaded with saporin-HRP) and to obtain the crude lysosomal fraction was carried out as described previously. Then, the crude lysosomal fractions $(15 \mu \mathrm{L})$ were incubated with $55 \mu \mathrm{L}$ translocation buffer in the presence of the same saponins as before (digitonin, $\alpha$-hederin or SA1641) at the final concentrations of $0.5,5,10,20,30,40$ and $50 \mu \mathrm{M}$ at 37 ${ }^{\circ} \mathrm{C}$ for $1 \mathrm{~h}$. Lysosomal suspensions were centrifuged at $20,000 \times g$ for $20 \mathrm{~min}$, and the amount of saporin-HRP present in the supernatants (released from the lysosomes) was determined by measuring the peroxidase activity (see Section 3.6). 


\subsection{Live Cell Imaging and Single Endo/Lysosome Analysis}

Live cell imaging was utilized to follow the endo/lysosomal escape of ${ }^{\text {Alexa }}$ saporin in the presence of triterpenoidal saponins. DMEM medium supplemented with 10\% FBS and 1\% PS containing 50,000 ECV-304 cells was added to a cell culture $\mu$-Dish $35 \mathrm{~mm}$, low (Ibidi, Martiensried, Germany) and cells were allowed to proliferate for $24 \mathrm{~h}$. Thereafter, the medium was removed, and cells were treated with $800 \mu \mathrm{L}$ medium in the presence of $1000 \mathrm{nM}{ }^{\text {Alexa }}$ saporin for $3 \mathrm{~h}$. Cells were provided with $8 \mu \mathrm{L}$ ( $1 \mathrm{mg} / \mathrm{mL}$ ) Hoechst 33342 (Life Technologies, Carlsbad, CA, USA) $30 \mathrm{~min}$ before the end of the incubation time. Additionally, cells were treated with $1 \mu \mathrm{L}$ CellMask (Invitrogen, Darmstadt, Germany) 5 min before the same incubation time finished. Cells were washed with live cell imaging solution (Invitrogen, Darmstadt, Germany) supplemented with $5 \mathrm{mM}$ D(+)glucose. The washing step was repeated twice. Then, cells were covered with $800 \mu \mathrm{L}$ live cell imaging solution, and cell culture dishes were fixed in a heating chamber to maintain the temperature at $37{ }^{\circ} \mathrm{C}$ and start the live cell imaging. Subsequently, SA1641 (final concentration of $10 \mu \mathrm{g} / \mathrm{mL}$ ) was added to cells and the endo/lysosomal escape of ${ }^{A l e x a}$ saporin was monitored for the following $3600 \mathrm{~s}$. Thereafter, a high concentration of SA1641 (final concentration of $80 \mu \mathrm{g} / \mathrm{mL}$ ) was provided to the cells, and the experiment was finished after observing its short-term effects.

Cells were visualized by laser scanning microscopy (LSM780, Axio Observer Z1, Carl Zeiss, Jena, Germany). The microscope was equipped with a Plan-Apochromat $63 \times / 1.40$ Oil objective, and focus stability was assured by Definite Focus (Carl Zeiss, Jena, Germany). Images were acquired by the software, ZEN 2010 (Carl Zeiss, Jena, Germany).

For the single endo/lysosome analysis, cells were monitored for $7200 \mathrm{~s}$ after the addition of SA1641 (final concentration of $10 \mu \mathrm{g} / \mathrm{mL}$ ). Endo/lysosomes that were constantly appearing in the

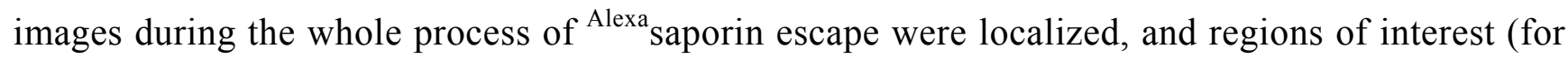
each single endo/lysosome) were defined using the software ImageJ (version 1.46r, NIH, USA). Regions of interest comprised the surroundings of the endo/lysosomes, but excluded the vesicle itself. Single endo/lysosome analysis was monitored from $2400 \mathrm{~s}$ to $4200 \mathrm{~s}$ after the addition of triterpenoidal saponin.

\section{Conclusions}

Three different reporters were studied for their ability to detect the endo/lysosomal escape of protein-based therapeutics. The reporters consisted of: (1) horseradish peroxidase (HRP), a protein presenting peroxidase activity; (2) Alexa Fluor 488 (Alexa), a small fluorophore emitting fluorescence; and (3) ricin A-chain (RTA), a toxin exhibiting cytotoxicity. The following conjugates were synthesized and characterized in vitro: saporin-HRP, ${ }^{\text {Alexa }}$ saporin and saporin-KQ-RTA. While HRP failed in reporting the endo/lysosomal escape of saporin in the presence of structurally-specific triterpenoidal saponins, Alexa Fluor 488 efficiently reported the endo/lysosomal escape of the toxin at a concentration of $1000 \mathrm{nM}$. Furthermore, Alexa Fluor 488 permitted the evaluation of the endo/lysosomal escape in a single endo/lysosome analysis. The usage of RTA as a reporter allowed detecting the process of endo/lysosomal escape with sensitivity down to $10 \mathrm{nM}$. The combination of the two successful reporters may act as a complementary technique to monitor the endo/lysosomal escape of a 
protein-based therapeutic at high protein concentrations (1000 nM with Alexa Fluor 488 reporter), as well as at concentrations in the low nanomolar range (10 $\mathrm{nM}$ with RTA reporter). The developed methods would be surely of great interest not only in toxin-based therapeutics, but also in the case of other protein therapeutics, wherein a reporter for the proper assessment of its endosomal escape is warranted. This would also facilitate a proper assessment of effective therapeutic concentrations, at least during in vitro assessment.

\section{Acknowledgements}

We acknowledge the financial support of the Deutsche Forschungsgemeinschaft (WE 4784/1-1, WE4784/2-1 and TH 1810/1-1), the Wilhelm Sander-Stiftung (2011.121.1) and the Stiftung der Deutschen Wirtschaft (grant to Benedicta von Mallinckrodt).

\section{Author Contributions}

Roger Gilabert-Oriol, Mayank Thakur, Matthias F. Melzig, Hendrik Fuchs and Alexander Weng designed the research. Roger Gilabert-Oriol and Alexander Weng conducted the experiments and analyzed the data. Mayank Thakur, Benedicta von Mallinckrodt, Cheenu Bhargava, Matthias F. Melzig and Hendrik Fuchs gave experimental advice and supported interpretation of results. Burkhard Wiesner and Jenny Eichhorst provided help in conducting confocal microscopy. Roger Gilabert-Oriol wrote the manuscript. Roger Gilabert-Oriol, Mayank Thakur, Hendrik Fuchs and Alexander Weng edited the manuscript. All authors approved the final paper.

\section{Abbreviations}

Alexa: $\quad$ Alexa Fluor 488;

DMEM: Dulbecco's modified Eagle's medium;

FBS: $\quad$ Foetal bovine serum;

HRP: $\quad$ Horseradish peroxidase;

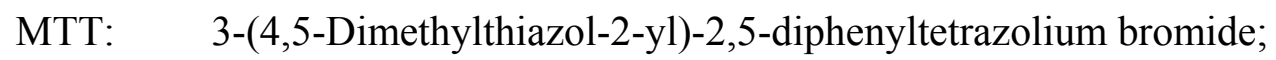

NTA: Nitrilotriacetic acid;

PS: $\quad$ Penicillin/streptomycin;

RIP: $\quad$ Ribosome-inactivating protein;

RTA: Ricin A-chain.

\section{Conflicts of Interest}

The authors declare no conflict of interest.

\section{References}

1. Fuchs, H.; Bachran, C.; Flavell, D. Diving through membranes: Molecular cunning to enforce the endosomal escape of antibody-targeted anti-tumor toxins. Antibodies 2013, 2, 209-235.

2. Sahay, G.; Alakhova, D.Y.; Kabanov, A.V. Endocytosis of nanomedicines. J. Control Release 2010, 145, 182-195. 
3. Sun-Wada, G.H.; Wada, Y. Vacuolar-type proton pump atpases: Acidification and pathological relationships. Histol. Histopathol. 2013, 28, 805-815.

4. Huotari, J.; Helenius, A. Endosome maturation. EMBO J. 2011, 30, 3481-3500.

5. Varkouhi, A.K.; Scholte, M.; Storm, G.; Haisma, H.J. Endosomal escape pathways for delivery of biologicals. J. Control Release 2011, 151, 220-228.

6. Muller, S.; Dennemarker, J.; Reinheckel, T. Specific functions of lysosomal proteases in endocytic and autophagic pathways. Biochim. Biophys. Acta 2012, 1824, 34-43.

7. Watson, P.; Spooner, R.A. Toxin entry and trafficking in mammalian cells. Adv. Drug Deliv. Rev. 2006, 58, 1581-1596.

8. Murphy, J.R. Mechanism of diphtheria toxin catalytic domain delivery to the eukaryotic cell cytosol and the cellular factors that directly participate in the process. Toxins 2011, 3, 294-308.

9. Moayeri, M.; Wickliffe, K.E.; Wiggins, J.F.; Leppla, S.H. Oxidized atp protection against anthrax lethal toxin. Infect. Immun. 2006, 74, 3707-3714.

10. Walsh, M.J.; Dodd, J.E.; Hautbergue, G.M. Ribosome-inactivating proteins: Potent poisons and molecular tools. Virulence 2013, 4, 774-784.

11. Słomińska-Wojewódzka, M.; Sandvig, K. Ricin and ricin-containing immunotoxins: Insights into intracellular transport and mechanism of action in vitro. Antibodies 2013, 2, 236-269.

12. Bolognesi, A.; Polito, L.; Scicchitano, V.; Orrico, C.; Pasquinelli, G.; Musiani, S.; Santi, S.; Riccio, M.; Bortolotti, M.; Battelli, M.G. Endocytosis and intracellular localisation of type 1 ribosome-inactivating protein saporin-s6. J. Biol. Regul. Homeost. Agents 2012, 26, 97-109.

13. Weng, A.; Thakur, M.; von Mallinckrodt, B.; Beceren-Braun, F.; Gilabert-Oriol, R.; Wiesner, B.; Eichhorst, J.; Bottger, S.; Melzig, M.F.; Fuchs, H. Saponins modulate the intracellular trafficking of protein toxins. J. Control Release 2012, 164, 74-86.

14. Barbieri, L.; Battelli, M.G.; Stirpe, F. Ribosome-inactivating proteins from plants. Biochim. Biophys. Acta 1993, 1154, 237-282.

15. Thakur, M.; Mergel, K.; Weng, A.; von Mallinckrodt, B.; Gilabert-Oriol, R.; Durkop, H.; Melzig, M.F.; Fuchs, H. Targeted tumor therapy by epidermal growth factor appended toxin and purified saponin: An evaluation of toxicity and therapeutic potential in syngeneic tumor bearing mice. Mol. Oncol. 2013, 7, 475-483.

16. Gilabert-Oriol, R.; Thakur, M.; von Mallinckrodt, B.; Hug, T.; Wiesner, B.; Eichhorst, J.; Melzig, M.F.; Fuchs, H.; Weng, A. Modified trastuzumab and cetuximab mediate efficient toxin delivery while retaining antibody-dependent cell-mediated cytotoxicity in target cells. Mol. Pharm. 2013, 10, 4347-4357.

17. Zarovni, N.; Vago, R.; Solda, T.; Monaco, L.; Fabbrini, M.S. Saporin as a novel suicide gene in anticancer gene therapy. Cancer Gene Ther. 2007, 14, 165-173.

18. Ratts, R.; Zeng, H.; Berg, E.A.; Blue, C.; McComb, M.E.; Costello, C.E.; vanderSpek, J.C.; Murphy, J.R. The cytosolic entry of diphtheria toxin catalytic domain requires a host cell cytosolic translocation factor complex. J. Cell Biol. 2003, 160, 1139-1150.

19. Haug, G.; Leemhuis, J.; Tiemann, D.; Meyer, D.K.; Aktories, K.; Barth, H. The host cell chaperone hsp90 is essential for translocation of the binary clostridium botulinum c2 toxin into the cytosol. J. Biol. Chem. 2003, 278, 32266-32274. 
20. Taylor, M.; Navarro-Garcia, F.; Huerta, J.; Burress, H.; Massey, S.; Ireton, K.; Teter, K. Hsp90 is required for transfer of the cholera toxin al subunit from the endoplasmic reticulum to the cytosol. J. Biol. Chem. 2010, 285, 31261-31267.

21. Thakur, M.; Weng, A.; Pieper, A.; Mergel, K.; von Mallinckrodt, B.; Gilabert-Oriol, R.; Gorick, C.; Wiesner, B.; Eichhorst, J.; Melzig, M.F.; et al. Macromolecular interactions of triterpenoids and targeted toxins: Role of saponins charge. Int. J. Biol. Macromol. 2013, 61, 285-294.

22. Vago, R.; Marsden, C.J.; Lord, J.M.; Ippoliti, R.; Flavell, D.J.; Flavell, S.U.; Ceriotti, A.; Fabbrini, M.S. Saporin and ricin a chain follow different intracellular routes to enter the cytosol of intoxicated cells. FEBS J. 2005, 272, 4983-4995.

23. Sikriwal, D.; Ghosh, P.; Batra, J.K. Ribosome inactivating protein saporin induces apoptosis through mitochondrial cascade, independent of translation inhibition. Int. J. Biochem. Cell Biol. 2008, 40, 2880-2888.

24. Eiklid, K.; Olsnes, S.; Pihl, A. Entry of lethal doses of abrin, ricin and modeccin into the cytosol of hela cells. Exp. Cell Res. 1980, 126, 321-326.

25. Heisler, I.; Keller, J.; Tauber, R.; Sutherland, M.; Fuchs, H. A cleavable adapter to reduce nonspecific cytotoxicity of recombinant immunotoxins. Int. J. Cancer 2003, 103, 277-282.

26. Weng, A.; Thakur, M.; Beceren-Braun, F.; Bachran, D.; Bachran, C.; Riese, S.B.; Jenett-Siems, K.; Gilabert-Oriol, R.; Melzig, M.F.; Fuchs, H. The toxin component of targeted anti-tumor toxins determines their efficacy increase by saponins. Mol. Oncol. 2012, 6, 323-332.

27. Gilabert-Oriol, R.; Thakur, M.; Weise, C.; Dernedde, J.; von Mallinckrodt, B.; Fuchs, H.; Weng, A. Small structural differences of targeted anti-tumor toxins result in strong variation of protein expression. Protein Expr. Purif. 2013, 91, 54-60.

28. Barbieri, L.; Brigotti, M.; Perocco, P.; Carnicelli, D.; Ciani, M.; Mercatali, L.; Stirpe, F. Ribosome-inactivating proteins depurinate poly(adp-ribosyl)ated poly(adp-ribose) polymerase and have transforming activity for 3t3 fibroblasts. FEBS Lett. 2003, 538, 178-182.

29. Weng, A.; Bachran, D.; Gorick, C.; Bachran, C.; Fuchs, H.; Melzig, M.F. A simple method for isolation of gypsophila saponins for the combined application of targeted toxins and saponins in tumor therapy. Planta Med. 2009, 75, 1421-1422.

30. Gilabert-Oriol, R.; Mergel, K.; Thakur, M.; von Mallinckrodt, B.; Melzig, M.F.; Fuchs, H.; Weng, A. Real-time analysis of membrane permeabilizing effects of oleanane saponins. Bioorg. Med. Chem. 2013, 21, 2387-2395.

(C) 2014 by the authors; licensee MDPI, Basel, Switzerland. This article is an open access article distributed under the terms and conditions of the Creative Commons Attribution license (http://creativecommons.org/licenses/by/3.0/). 